\title{
Estimation of Emissions Due to Two-Stroke Engines in Khartoum
}

\author{
Hunaida Abd Elbage Abazar Ahmed, Kamal Eldin Eltayeb Yassin \\ Chemical Engineering Department, University of Khartoum, \\ Sudan
}

\begin{abstract}
This study intended measuring the emissions of carbon monoxide and particulate matter from two-stroke engines in Khartoum. Field data were collected through interviews, questionnaire, measurements and laboratory tests. Federal Test Procedure, United Nations Economic Commission and Japanese procedures have been applied to simulate the emissions form two-stroke engines on road. The measurements were carried out by using electronic portable equipment to measure the concentrations of pollutants in an ambient air. National Ambient Air Quality Standards and Air Quality Index were applied on measured emissions to determine and compare the risk rating of two-stroke engines emissions. We found that, different sites suffered from high concentration of carbon monoxide, particulate matter of $\mathbf{1 0}$ and $\mathbf{2 . 5}$ microns in diameter due to emissions from two-stroke engines. At the peak period from $12: 00 \mathrm{pm}$ to 7:00 pm, the average concentration of carbon monoxide, particulate matter of 10 and 2.5 microns in diameter exceeds the maximum permissible exposure limit by $568 \%, 265 \%$ and $579 \%$, respectively. It was concluded to, the using of two-stroke engines contribute to one of the environmental problems in Sudan. Therefore, it was recommended to produce bio-lubricant oils for two-stroke engines instead of petroleum-based oils. In addition, standards and regulations must be more binding and restrictive to control the emissions, misuse of lubricants and raise awareness among users of two-stroke engines in Khartoum.
\end{abstract}

Keywords: Air pollutants, Two-stroke engines, Carbon monoxide, Particulate matter, Air Quality Index.

\section{INTRODUCTION}

The exhaust of automobiles is one of the major contributors to the world's air pollution problem [1]. Two-stroke engines emit significant amounts of Carbon Monoxide (CO) Particulate matter (PM), Hydrocarbon (HC), Nitrogen Oxides (NOx) and Sulfur Dioxide $\left(\mathrm{SO}_{2}\right)[2,3,4]$. According to National Ambient Air Quality Standards, those pollutants are known as criteria pollutants that had serious impacts on human health and environment [5, 6]. Two-stroke engines are considered total-loss of type lubricating systems so the oil is mixed with fuel [7].

This study was arranged in two steps:

\section{METHODOLOGY}

The first step is to study the current status of emissions from two-stroke engines due to non-availability data on pollution due to it in Khartoum.

$>$ The second step is to simulate the emissions from two-stroke engines on road by applying the most common international procedures, which are U.S Federal test procedure, United Nations Economic Commission for Europe and Japanese test procedure.

\subsection{Operational area and study location}

Khartoum state was selected to study the effect of two stroke engines on an ambient air quality because it has the largest proportion of vehicles that have a two-stroke engine in Sudan. For the accuracy purposes, the operational area was divided into sub-locations that are Khartoum, Khartoum North and Omdurman, each one contained 50 sites.

\subsection{Sampling and data collection}

Data Quality Objectives (DQO) was followed as EPA recommended for systematic planning of environmental data collection [8]. Field data were collected through interviews, questionnaire, measurements and laboratory investigations. The questionnaire was designed to measure the degree of air pollution perception between two-stroke engines users and precisely represented appropriate data of the environmental problem that was investigated.

Air sampling is based on capturing the contaminant from a known volume of air, measuring the amount of contaminant captured, and expressing it as a concentration. The air is passed through a filter medium (normally a paper for solid contaminants and a sorbent for gases). The volume of air is measured against the amount of contaminant captured. This gives the concentration, which is expressed either as milligrams per cubic meter $(\mathrm{mg} / \mathrm{m} 3)$ or parts per million $(\mathrm{ppm})$ [9].

The sampling design was built based on judgmental sampling method and to obtain 4 samples on each sampling site at early morning, mid-day, early evening and at night. 


\subsection{Laboratory instruments}

I. Two-stroke engines

The auto rickshaw is 3-wheeler vehicle with a 2-sttroke engine. It is considered a common form of urban transport as a vehicle for hire and for private use in many countries around the world, especially developing countries. Bajaj Auto is the world's largest auto rickshaw manufacturer. In Sudan, it is called "Raksha" and it is the most common mean of transportation.

\section{Sensitive gas analyzer; Aeroqual series 500}

The series 500 air quality sensor enables accurate real-time surveying of common outdoor air pollutants, all in an ultraportable handheld monitor (Figure 2-1). Air quality professional typically use the series 500 for short-term air quality studies and carrying out checks on pollution "hot spots". The series 500 can also be deployed for short-term fixed monitoring by adding an optional outdoor enclosure [10]. Here it was used to measure the amount of CO concentration surrounding twostroke engines.

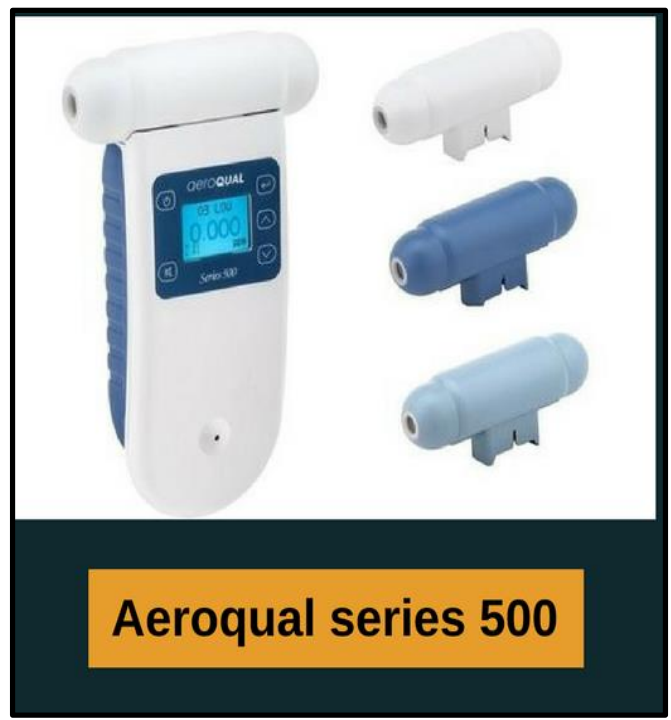

Figure 2-1: Sensitive gas analyzer

\section{Particles analyzer; Aerocet 831}

The Aerocet 831 is a small, lightweight, battery operated, handheld mass profiler. This instrument simultaneously monitors PM1, PM2.5, PM4, PM10 and TSP levels. The multifunction rotary dial provides simple and efficient operation. The internal battery pack provides 8 hours of continuous operation. The Aerocet 831 stores up to 2,500 sample events, which can be viewed on the display or exported to a computer via the USB port (Figure 2-2). The lightweight instrument is only 28 ounces that it is perfect survey tool for a wide range of applications [11].

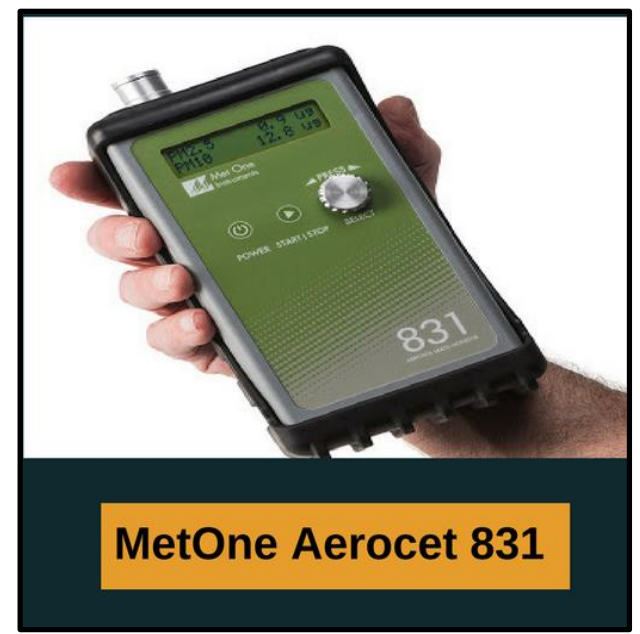

Figure 2-2: Particles analyzer 
IV. $\quad$ Meter and stopwatch

V. $\quad$ Lubricant oil (Fuchs Titan) Table 2-1)

Table 2-1: Titan Super GT specifications

\begin{tabular}{|l|l|l|l|}
\hline Properties & Unit & Value Test & Method \\
\hline Flash Point & & Commercial oil & \\
\hline Pour Point & ${ }^{\circ} \mathrm{C}$ & 246 & ASTM D 92 \\
\hline Dynamic Viscosity @ $-15^{\circ} \mathrm{C}$ & ${ }^{\circ} \mathrm{C}$ & -24 & ASTM D 97 \\
\hline Density @ $35^{\circ} \mathrm{C}, 15^{\circ} \mathrm{C}$ & $\mathrm{mPa} . \mathrm{s}$ & 8500 & ASTM D 5293 \\
\hline Kinematic Viscosity @ $40^{\circ} \mathrm{C}$ & $\mathrm{g} / \mathrm{ml}^{2} / \mathrm{s}$ & 0.879 & ASTM D 4052 \\
\hline Kinematic Viscosity @ $100{ }^{\circ} \mathrm{C}$ & $\mathrm{mm}^{2} / \mathrm{m}$ & 180 & ASTM D 445 \\
\hline Viscosity Index & $\mathrm{mm}^{2} / \mathrm{s}$ & ASTM D 445 \\
\hline
\end{tabular}

\subsection{Analytical techniques}

I. Microsoft Excel office was used for calculations

II. National Ambient Air Quality Standards and Air Quality Index (Equation 2-1) were applied for analyzing and comparing the risk rating of two-stroke engines emissions.

Equation 2-1: Air Quality Index Equation [12]

$$
\mathrm{AQI}=\frac{(\mathrm{PMobs}-\mathrm{PMmin})(\mathrm{AQImax}-\mathrm{AQImin})}{(\mathrm{PMmax}-\mathrm{PMmin})}+\mathrm{AQImin}
$$

Where;

$\mathrm{PM}_{\text {obs: }}$ observed 24-hour average concentration.

$\mathrm{PM}_{\max }$ : maximum concentration of AQI color category that contain $\mathrm{PM}_{\mathrm{obs}}$.

$\mathrm{PM}_{\text {min }}$ : minimum concentration of AQI color category that contain $\mathrm{PM}_{\mathrm{obs}}$.

$\mathrm{AQI}_{\text {min: }}$ maximum AQI value for color category that corresponds to $\mathrm{PM}_{\mathrm{obs}}$.

$A Q I_{\text {min }}$ : minimum AQI value for color category that corresponds to $\mathrm{PM}_{\mathrm{obs}}$.

Table 2-2: Air Quality Index [12]

\begin{tabular}{|l|l|}
\multicolumn{1}{|c|}{$\begin{array}{c}\text { Air Quality Index } \\
\text { (AQI) Values }\end{array}$} & \multicolumn{1}{|c|}{ Levels of Health Concern } \\
\hline When the AQI is in this range: & ..air quality conditions are: \\
\hline 0 to 50 & Good \\
\hline $\mathbf{5 1}$ to 100 & Moderate \\
\hline 101 to 150 & Unhealthy for Sensitive Groups \\
\hline 151 to 200 & Unhealthy \\
\hline 201 to 300 & Very Unhealthy \\
\hline 301 to 500 & Hazardous \\
\hline
\end{tabular}




\section{RESULTS AND DISCUSSION}

3.1 Analysis and discussion of questionnaire

In spite of, 77\% of two-stroke engines users are either young graduates or still studying, their information is very poor in lubricants. Not only that, but they have a misconception about the amount of oil used to blend with the fuel, which is "the greater the amount of oil mixed, the performance of two-stroke engines work optimized". In addition to that, poor quality oils are used as lubricant for two-stroke engines such as; four-stroke motor oils, which are not prepared for blending with fuel or combustion (Figure 3-1, Figure 3-2).

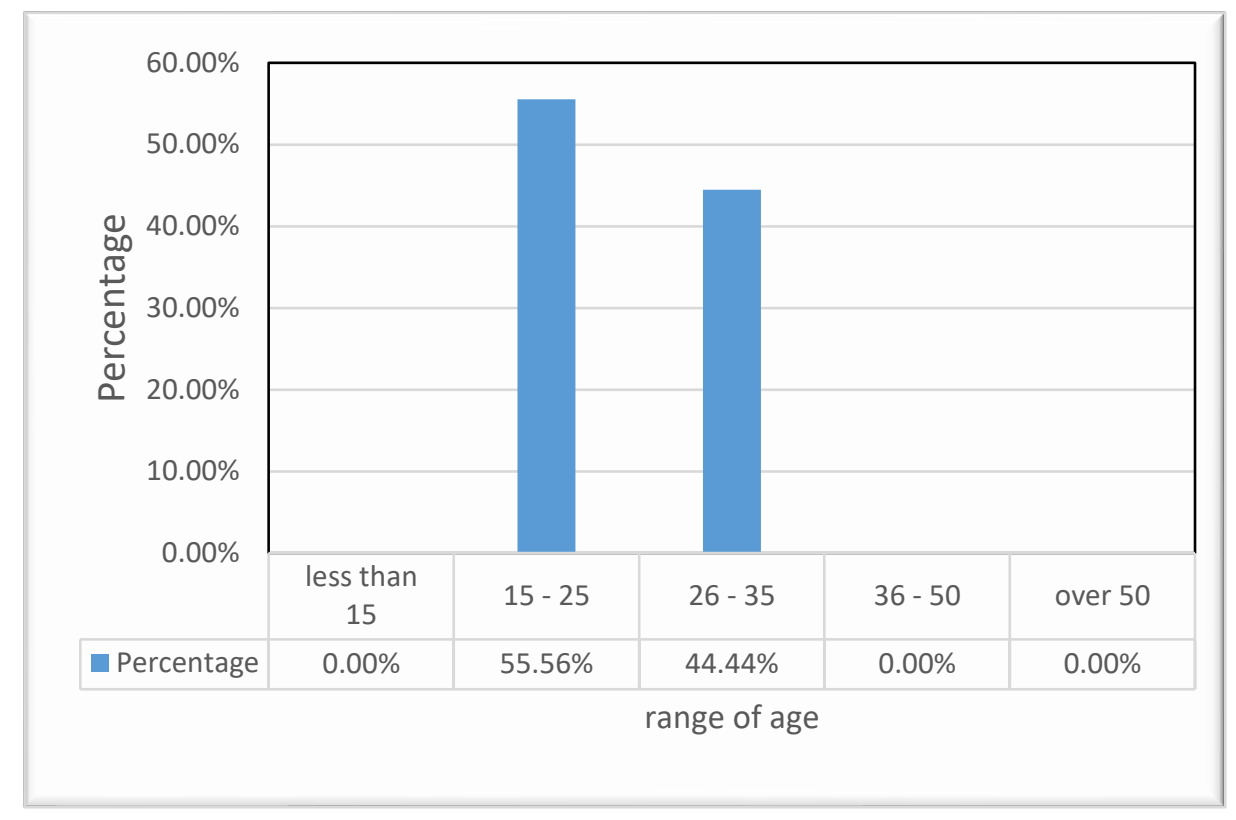

Figure 3-1: Age of two-stroke engines users

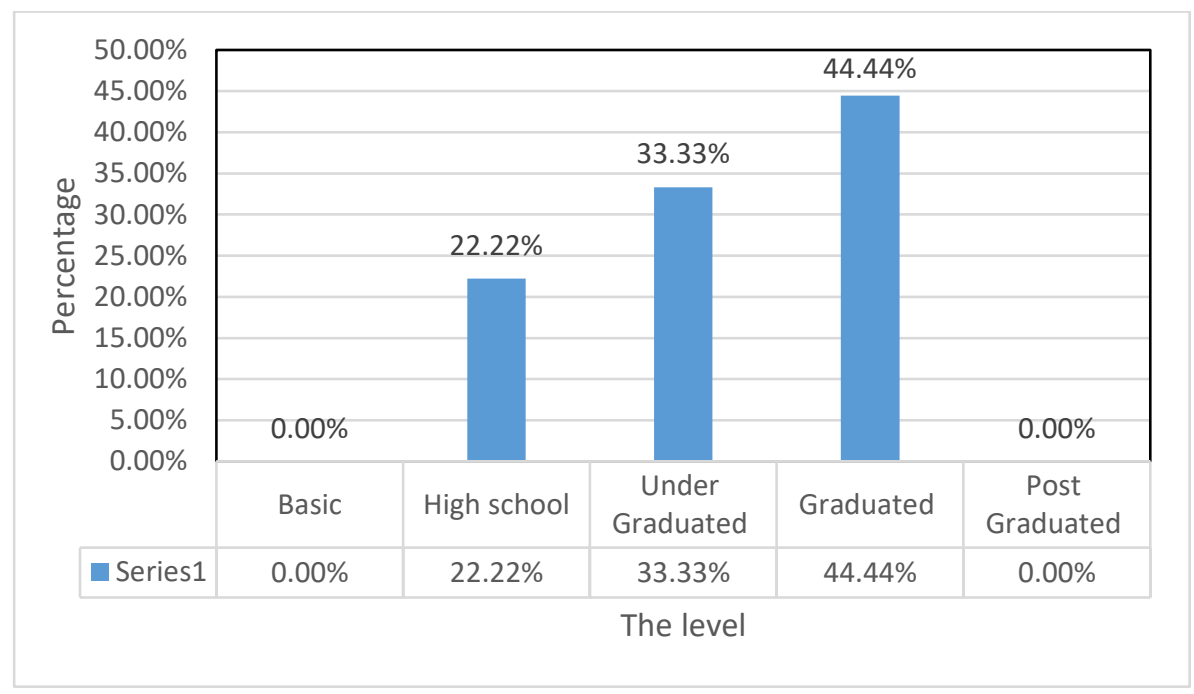

Figure 3-2: Educational level of two-stroke engines' users under study

$66.7 \%$ of users of two-stroke engines have awareness about the effect of contaminated drinking water and food on their lives. Moreover, most of them complained of contaminated drinking water but the authorities did not care. 50\% of the sample was aware of the impact of contaminated surface water on their health but believe that:" surface water treats itself from any pollution so, there is no negative impact on water quality or ecological life". Only people with respiratory or heart diseases who are concerned with air pollution and greenhouse effects (Figure 3-3). 


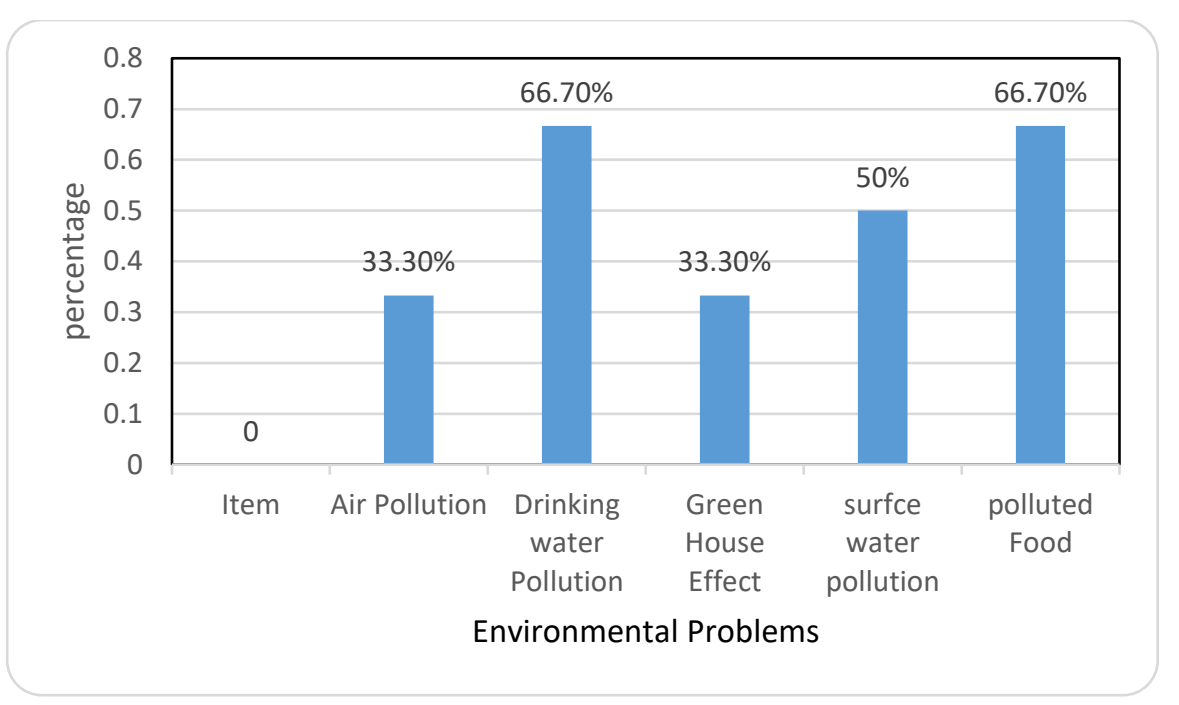

Figure 3-3: The degree of awareness of two-stroke engines users towards environmental issues

\subsection{Results of Measurements from Field Tests}

\subsubsection{On Road}

According to the sampling design, it was observed that, the concentration levels of measured pollutants in the sampled population were differed from period to period according to people activities during the day. The highest concentration levels of $\mathrm{CO}$ were found in the mid-day for all sampled populations, while at early morning, the concentration level of it was recorded the lowest values compared with the others in the target population. Even that they were still extremely exceeded the maximum permissible exposure limits (PEL) at different periods during the day (Figure 3-4, Figure 3-5 and Figure 3-6).

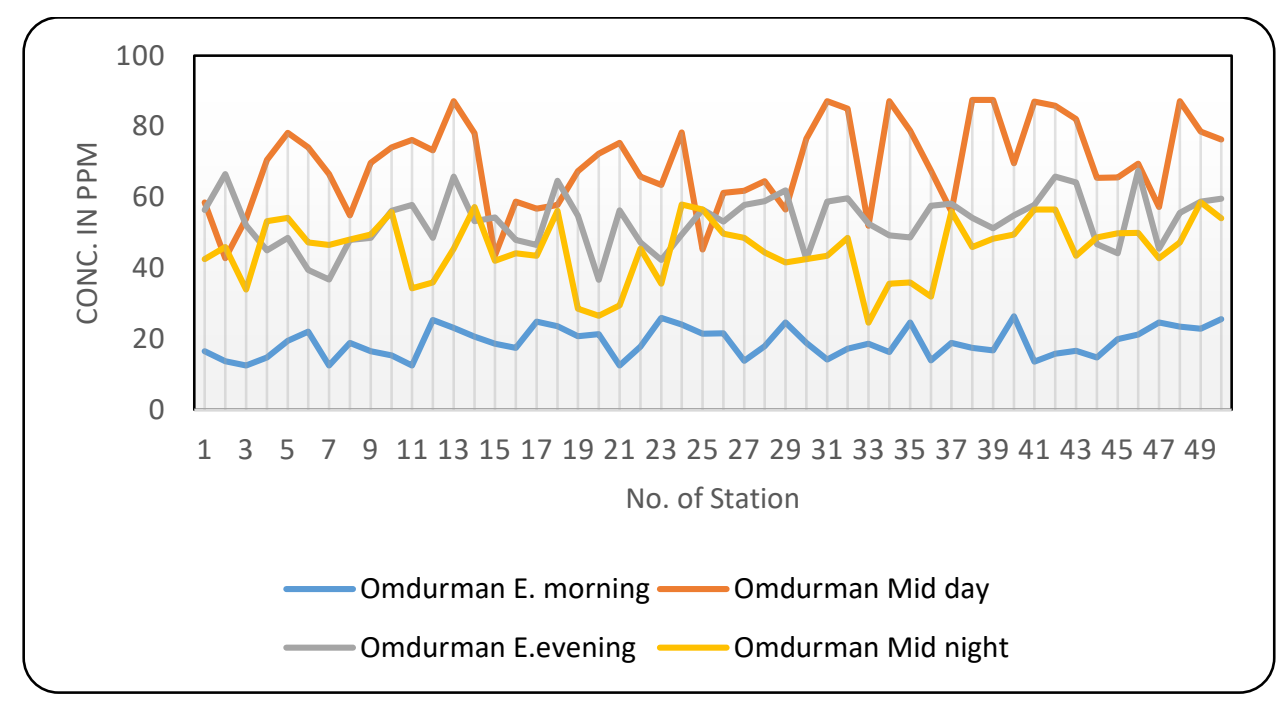

Figure 3-4: Carbon monoxide level of sampled population according to the sampling design in Omdurman

In addition to that, $\mathrm{PM}_{10}$ and $\mathrm{PM}_{2.5}$ were followed the same carbon monoxide track in their fluctuations during daytime (Figure 3-8 and Figure 3-9). 


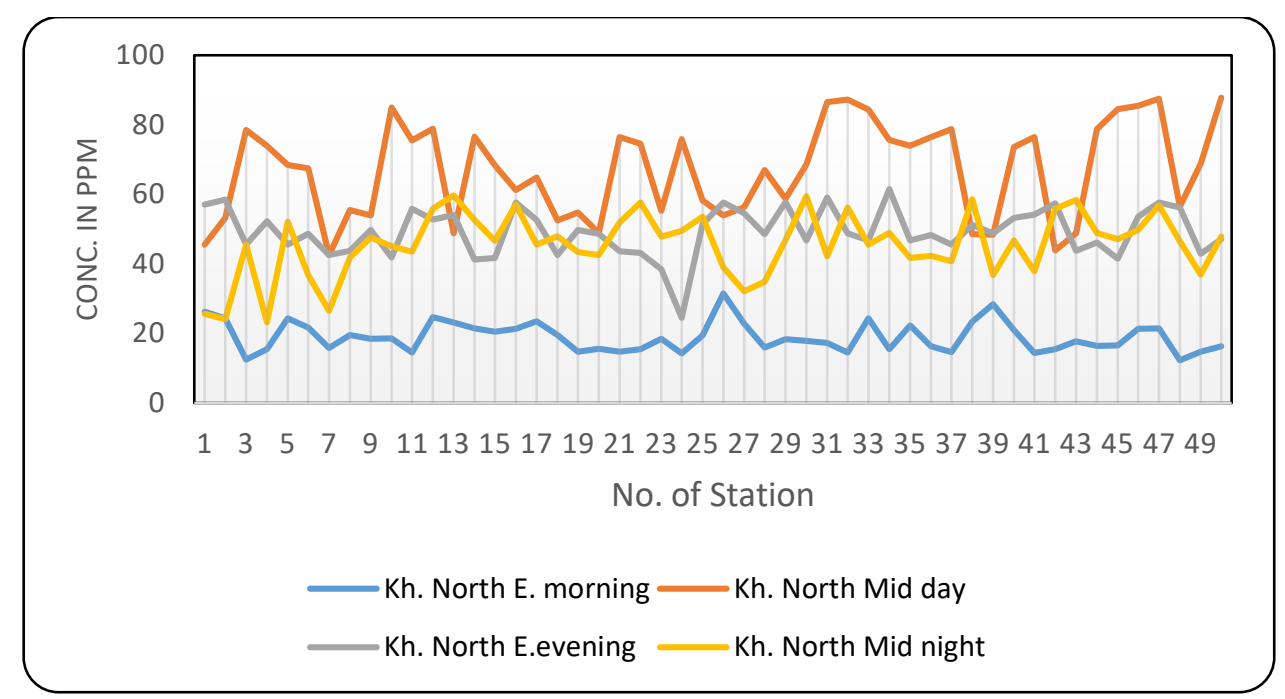

Figure 3-5: Carbon monoxide level of sampled population according to the sampling design in Khartoum north

It was concluded that, there was a direct relationship between the people activities during the day and the amount of emissions in an ambient air.

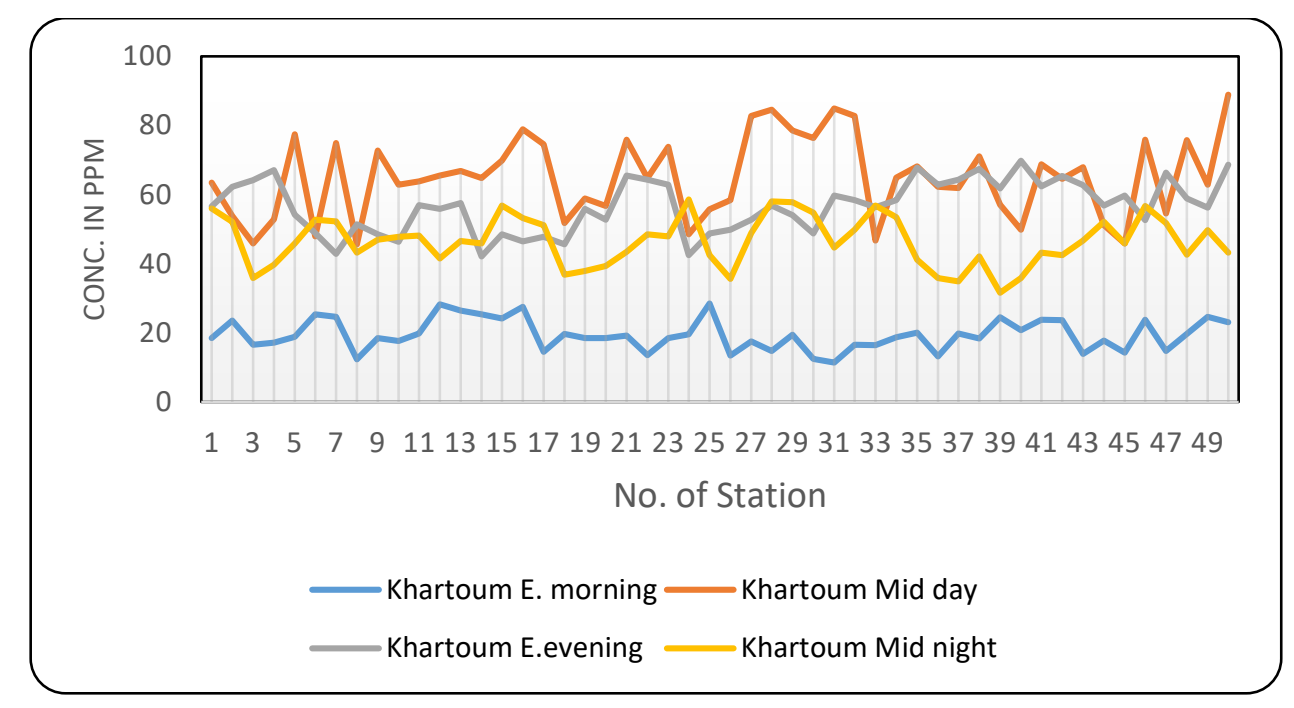

Figure 3-6: Carbon monoxide level of sampled population according to the sampling design in Khartoum

$>$ Air quality index calculation

Air quality index (AQI) was calculated to demonstrate the health effects of emissions on people in the target population. To calculate AQI, an average concentration level of $\mathrm{CO}, \mathrm{PM}_{10}$ and $\mathrm{PM}_{2.5}$ at different locations were obtained and shown in Figure 3-7, Figure 3-8 and Figure 3-9 respectively. The observed average concentration of pollutants were applied in Equation 2-1) to get AQI for the target population according to the sampling design (Table 3-1). 


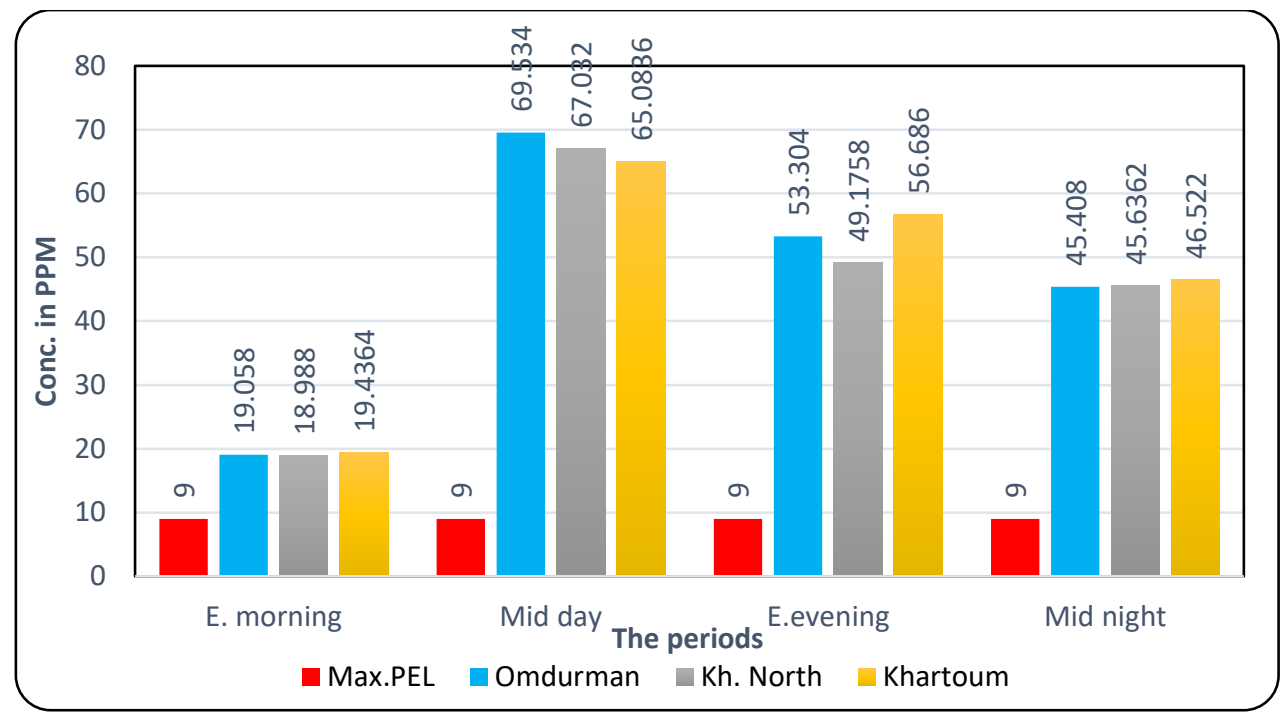

Figure 3-7: Average concentration of $\mathrm{CO}$ according to the sampling design for the target population

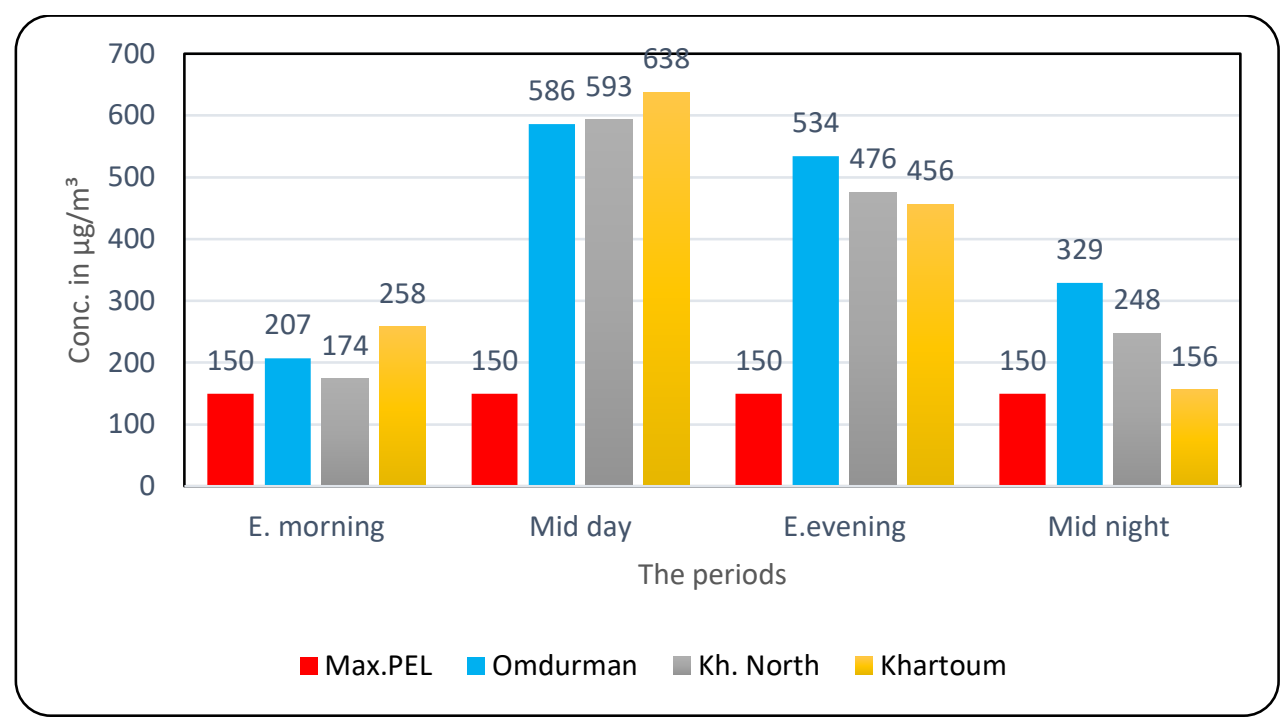

Figure 3-8: Average concentration of $\mathrm{PM}_{10}$ according to the sampling design for the target population

It was found that, during the day except in the early morning, the target population is suffered from high contamination of CO. This degree of $\mathrm{CO}$ concentration causes serious aggravation of cardiovascular symptoms such as chest pain, in people with cardiovascular disease and impairment of strenuous activities in general population. Although, the concentration of CO in the early morning was lower than the rest of the day, the ambient air was found to be very unhealthy for people had been suffering from respiratory or heart diseases, the elderly and children. Therefore, people with cardiovascular disease such as angina should avoid exertion and everyone else should limit heavy exertion. 


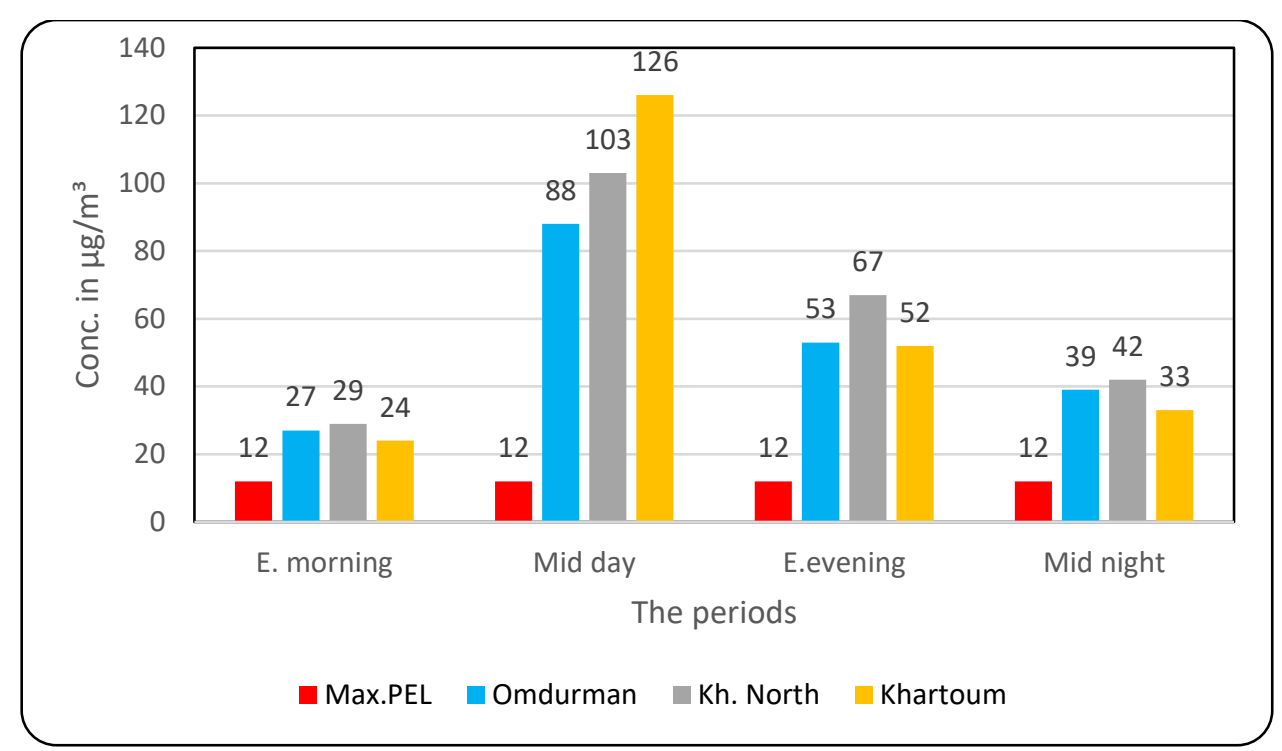

Figure 3-9: Average concentration of $\mathrm{PM}_{2.5}$ according to the sampling design for the target population

Table 3-1: AQI of average $\mathrm{CO}, \mathrm{PM}_{10}$ and $\mathrm{PM}_{2.5}$ concentration of the sampled population

\begin{tabular}{|l|l|c|c|c|c|}
\hline \multirow{2}{*}{ The pollutants } & \multicolumn{1}{|c|}{ Location } & \multicolumn{4}{c|}{ AQI } \\
\cline { 2 - 5 } & & Early morning & Mid-day & Early evening & Mid night \\
\hline \multirow{3}{*}{$\mathrm{CO}$} & Omdurman & 224 & $>\mathbf{5 0 0}$ & $>500$ & 450 \\
\cline { 2 - 6 } & Khartoum north & 218 & $>500$ & 487 & 452 \\
\cline { 2 - 6 } & Khartoum & 227 & $>500$ & $>500$ & 451 \\
\hline \multirow{2}{*}{$\mathrm{PM}_{10}$} & Omdurman & 127 & 482 & 430 & 188 \\
\cline { 2 - 6 } & Khartoum north & 110 & 489 & 365 & 147 \\
\cline { 2 - 6 } & Khartoum & 152 & $>500$ & 340 & 101 \\
\hline $\mathrm{PM}_{2.5}$ & Omdurman & 82 & 168 & 144 & 110 \\
\cline { 2 - 6 } & Khartoum north & 87 & 176 & 157 & 95 \\
\cline { 2 - 6 } & Khartoum & 76 & 187 & 142 & 95 \\
\hline
\end{tabular}

In the mid-day and early evening of the day, the samples that were absorbed through the filter showed a high concentration of $\mathrm{PM}_{10}$. That hazardous level is very dangerous for the symptoms of respiratory system and worsening the lung diseases. Therefore, everyone in the target population should any outdoor exertion and people with respiratory diseases should remain indoor.

The effect of $\mathrm{PM}_{10}$ contamination on ambient air in the early morning and mid-night was similar to $\mathrm{PM}_{2.5}$ in the middle of night and in the early evening. It was unhealthy for people with respiratory or heart disease, the elderly and children because it increases the likelihood of respiratory symptoms, aggravation of the lung disease and premature mortality in persons with cardiopulmonary disease.

In the mid-day, the concentration of $\mathrm{PM}_{2.5}$ in the air was found to be unhealthy, leading to the aggravation of heart or lung disease and premature mortality in people with cardiopulmonary disease and the elderly. In addition, the respiratory effects of the target population may be eroded, so everyone should reduce the prolonged effort.

The lowest level of $\mathrm{PM}_{2.5}$ contamination in the target population was measured in the early morning, which is considered relatively safe for people, but they have to be careful to maintain their health. 


\subsubsection{On laboratory}

1. FTP (US) procedure

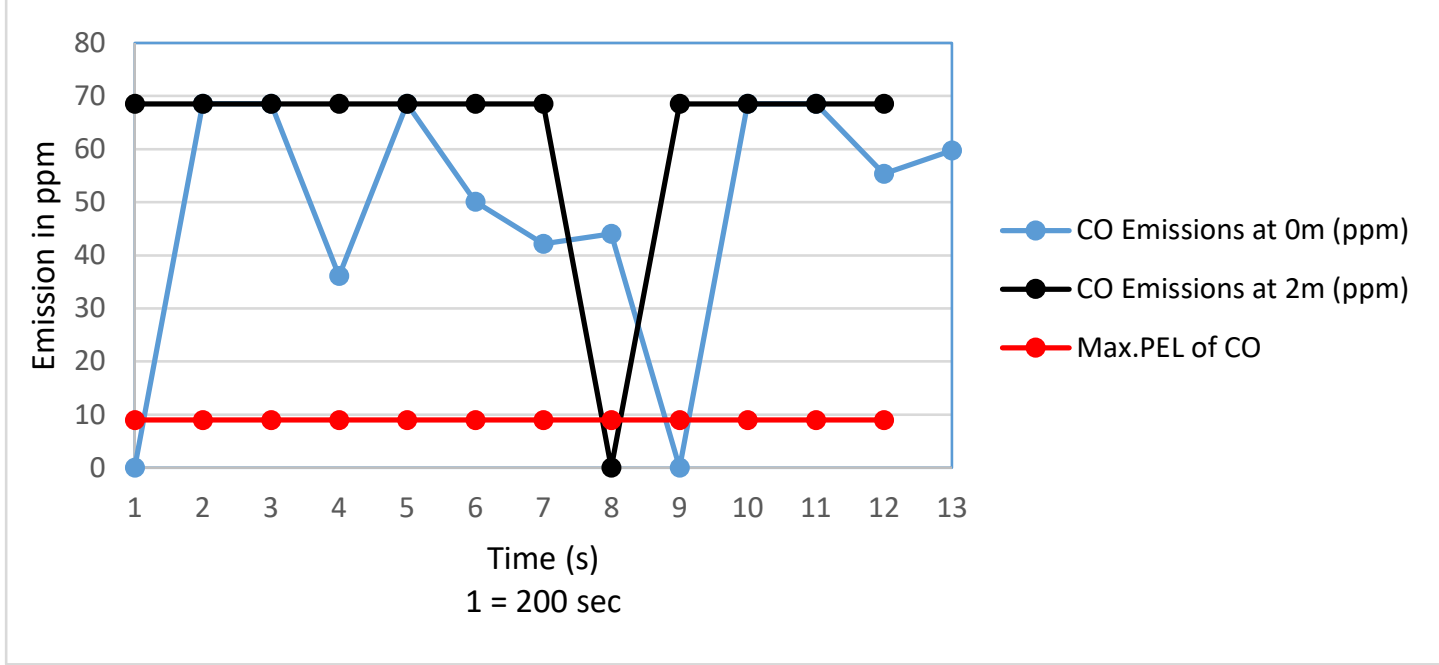

Figure 3-10: FTP (US) procedure for CO emissions from two-stroke engine under test at different distance from exhaust pipe, zero concentration at stopped time.

In Figure 3-10; it was observed that the amount of $\mathrm{CO}$ concentration start at the highest level and decreased over a time when the speed of engine was decreased until the engine eventually was turned off. The measurements at a distance of 2 meters was done after the measurement at a distance of zero meter had been taken, so it was noted that the area was saturated with concentration of CO more over NAAQS for carbon monoxide concentration level in an ambient air, which it is very dangerous, and harmfully to human health and environment.

\section{European procedure}

European driving cycle is simple and consisting of stable speeds. Although this procedure is considered the ideal position in the simulation of emissions, the concentration of CO level from two-stroke engines as result of using the commercial lubricant oils was very harmful and serious effects (Table 3-2).

Table 3-2: CO emissions based on European procedure from two-stroke engines because of using the commercial lubricant oil

\begin{tabular}{|c|c|}
\hline Reading & $\begin{array}{c}\text { Emissions of CO using a commercial } \\
\text { lubricant oil (ppm) }\end{array}$ \\
\hline CO Emissions at $0 \mathrm{~m}(\mathrm{ppm})$ & 73.74 \\
\hline CO Emissions at $2 \mathrm{~m}(\mathrm{ppm})$ & 50.52 \\
\hline
\end{tabular}

\section{Japanese procedure}

In this procedure, it was observed that the amount of $\mathrm{CO}$ emissions was very high at the start of the experiment (Table 3-3); this was due to the nature of this procedure cycles that are allowed the engines to warm up at a high speed.

Table 3-3: CO emissions based on Japanese procedure from two-stroke engines because of using the commercial lubricant oils

\begin{tabular}{|c|c|c|c|}
\hline \multicolumn{2}{|c|}{} & CO Emissions at 0m (ppm) & CO Emissions at 2m (ppm) \\
\hline \multirow{3}{*}{10 -mode } & $1^{\text {st }}$ segment & 77.82 & 54.47 \\
\cline { 2 - 4 } & $2^{\text {nd }}$ segment & 43.56 & 39.43 \\
\cline { 2 - 4 } & $3^{\text {rd }}$ segment & 26.81 & 25.18 \\
\hline \multicolumn{2}{|c|}{ 15-mode segment } & 24.49 & 22.68 \\
\hline
\end{tabular}

4. Air quality index

The average concentration of $\mathrm{PM}_{10}$ and $\mathrm{PM}_{2.5}$ was shown in Figure 3-11 and Figure 3-12. AQI was calculated using Equation 2-1 and displayed in Table 3-4. 


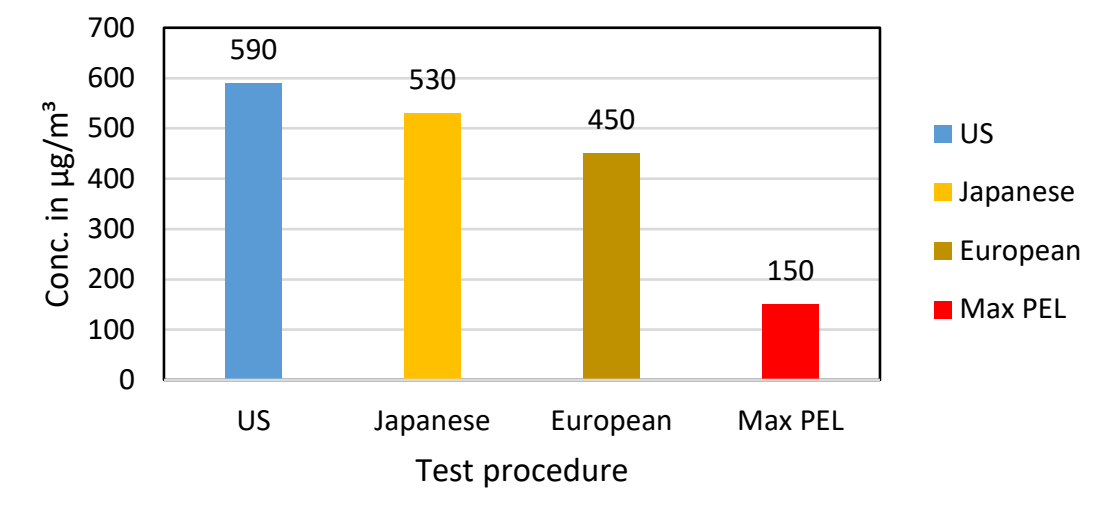

Figure 3-11: The average concentration of $\mathrm{PM}_{10}$ emissions from two-stroke engines by applying international procedures in the laboratory

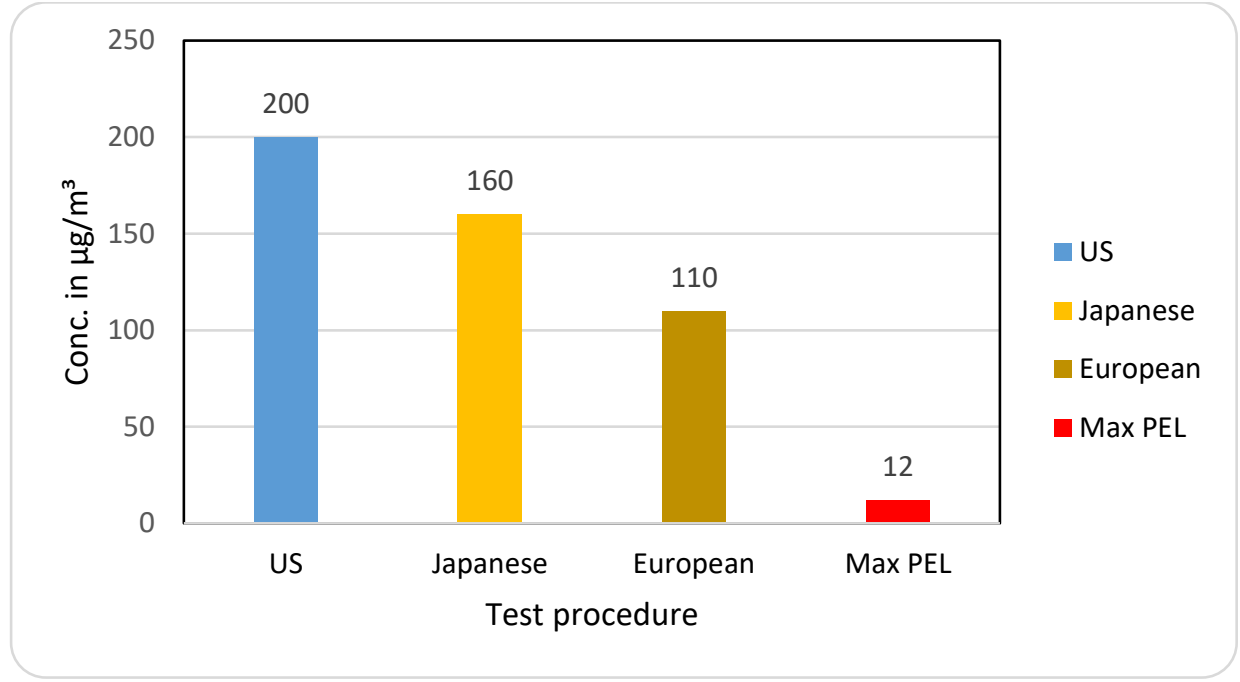

Figure 3-12: The average concentration of $\mathrm{PM}_{2.5}$ emissions from two-stroke engines by applying international procedures in the laboratory

For the different applicable procedures, the concentration of $\mathrm{PM}_{10}$ in ambient air was found to be hazardous and was consistent with the results obtained from road measurements (Table 3-1). In addition, the concentration of $\mathrm{PM}_{2.5}$ in ambient air through the application of US and Japanese procedures was consistent with results obtained from road measurements, while the results obtained from the European procedure, were contrary to reality because they assume the ideal movement in emulating emissions.

Table 3-4: AQI for the emissions of particulate matter from two-stroke engines through the application of international procedures

\begin{tabular}{|c|c|c|}
\hline \multirow{2}{*}{ Procedure } & \multicolumn{2}{|c|}{ AQI } \\
\cline { 2 - 3 } & $\mathrm{PM}_{10}$ & $\mathrm{PM}_{2.5}$ \\
\hline US & 489 & 250 \\
\hline Japanese & 426 & 210 \\
\hline European & 332 & 179 \\
\hline
\end{tabular}

\section{CONCULUSION}

The users of two-stroke engines in Khartoum use inappropriate quantity of lubricant oil due to their lack of knowledge about the correct amount to be used and their perception that "more lubricant will provide greater protection against piston seizure". The problem is further enhanced because they tend to use excessive oil of poor quality because it is economically feasible.

All of that and else contribute to environmental problems in Sudan due to two-stroke engines using. The amount of pollutants are emitted by those engines exceeds the safety levels indicated by National Ambient Air Quality Standards (NAAQS) and World 
Health Organization (WHO). Therefore, lubricant oils that were being used for two-stroke engines in Sudan it was inappropriate for the environment and human health and should be replaced by eco-friendly lubricants.

\section{ACKNOWLEDGEMENT}

We would like to acknowledge grant-funding support by Dr. Elfadil Elmelik in memory of the late son Eng. Elfatih. We are indebted to semi-final chemical engineering students who helped us in laboratory tests.

\section{REFERENCES}

[1] W. W. Pulkrabek, Engineering Fundamentals of the Internal Combustion Engine, 1st ed., platteville: University of Wisconsin, 2009, pp. 5, 30.

[2] J. B. Heywood, Internal Combustion Engine Fundamentals, vol. II, Massachusetts: Massachusetts Institute ofTechnology, Apr.2001, pp. 567-572.

[3] J McDonald, "Evaluation of Emissions from Asian 2-stroke Motorcycles," Society of Automotive Engineers, 2005.

[4] Technical Bulletin 5, "Exhaust Emissions of Toxic Air Pollutants using Reformulated Gasolines," Auto/oil coordinating Research Council Inc, Georgia, 2010.

[5] R. A. Buchholz, "National Ambient Air Quality Standards," Britannica, 26 May 2017. [Online]. Available: http://www.Britannica.com. [Accessed 30 April 2018].

[6] W. Kindzierski, P. Chelme-Ayala and E.-D. M. Gamal, "Ambient Air Quality Data Summary and Trend Analysis," Wood Buffalo Environmental Association, Alberta, 2009.

[7] AMSOIL, "Two-cycle Engine Applications and Lubrication Needs," AMSOIL Action News, July 2001.

[8] EPA, "Guidance on Choosing a Sampling Design for Environmental Data Collection," Office of Environmental Protection Information, Washington, 2002.

[9] SKC, "An Introduction to Air Sampling," July 2015. [Online]. Available: www.skcltd.com. [Accessed 14 June 2017].

[10] S. J. Vuetilovoni, "Portable Monitors User Guide," Aeroqual limited, Auckland, 2017.

[11] J. Elseth, "AEROCET 831 manual," Met One Instruments, Inc, Oregon, 2014.

[12] E. Salvador, "Air Quality Index," San Salvador, 2012. 